\title{
Kajian Kondisi Lahan Pasang Surut Pada Irigasi Rawa Palambahen Provinsi Kalimantan Tengah
}

\section{Study Of Tidal Land Conditions In Palambahen Swamp Irrigation, Central Kalimantan Province}

\author{
Lilik Ariyanto \\ ${ }^{1}$ Program Studi Teknik Sipil Universitas Sang Bumi Ruwa Jurai \\ Email: lilikariyanto2020@gmail.com
}

\begin{abstract}
Abstrak
Irigasi Rawa Palambahen merupakan irigasi rawa pasang surut yang berpotensi sebagai penyuplai produksi beras di Kabupaten Pulang Pisau Provinsi Kalimantan Tengah. Kajian kondisi lahan dan jaringan perlu dilakukan untuk mengetahui potensi pengembangan dan meningkatkan kapasitas produksi padi. Metode yang digunakan untuk mengkaji kondisi lahan dan jaringan adalah metode pengamatan dan pengambilan sampel terhadap penggunaan lahan dan pengamatan pasang surut untuk menganalisis ketercapaian air pada areal lahan pertanian terjauh. Hasil penelitian diketahui bahwa selama periode tahun 2014 sampai tahun 2019, penggunaan lahan sawah mengalami penurunan sebesar $239 \mathrm{Ha}$, kebun mengalami peningkatan sebesar $1284.59 \mathrm{Ha}$, belukar mengalami penurunan $1111.75 \mathrm{Ha}$ dan pemukiman mengalami peningkatan sebesar $66.16 \mathrm{Ha}$. Tingkat kesesuaian lahan termasuk dalam kategori sesuai untuk padi dan palawija serta perkebunan tanaman keras di bagian Timur. Hasil pengamatan dan analisis data pasang surut diketahui bahwa elevasi pasang tertinggi berada pada $+5 \mathrm{mdpl}$, sehingga areal pertanian pada elevasi di atas $+5 \mathrm{mdpl}$ tidak dapat terairi oleh air pasang, maka perlu perencanaan pintu penahan di bagian tengah saluran atau dilakukan dengan pemanfaatan pompa sesuai dengan kapasitas yang diperlukan.
\end{abstract}

Kata kunci: Penggunaan Lahan, Pasang Surut, Pompa

\begin{abstract}
Palambahen Swamp Irrigation is a tidal swamp irrigation that has the potential to supply rice production in Pulang Pisau Regency, Central Kalimantan Province. Land and network condition studies need to be carried out to determine the potential for development and increase rice production capacity. The method used to assess land and network conditions is the method of observation and sampling of land use and tidal observations to analyze the achievement of water in the farthest agricultural land area. The results of the study are known that during the period of 2014 to 2019, the use of paddy fields decreased by $239 \mathrm{Ha}$, gardens increased by $1284.59 \mathrm{Ha}$, shrubs decreased by $1111.75 \mathrm{Ha}$ and settlements increased by $66.16 \mathrm{Ha}$. The level of land suitability is included in the appropriate category for rice and secondary crops and tree plantations in the East. The results of observations and analysis of tidal data show that the highest tide elevation is at +5 masl, so that agricultural areas at elevations above +5 masl can not be irrigated by tides, it is necessary to plan the gate at the middle of the channel or be carried out with the use of pumps in accordance with the required capacity.
\end{abstract}

Keywords: Land Use, Tides, Pumps 


\section{PENDAHULUAN}

Daerah rawa yang terletak di kawasan pengembangan Jaringan rawa Kabupaten Pulang Pisau sebagian telah dimanfaatkan oleh masyarakat lokal sebagai lahan tanaman pangan, palawija dan lahan pemukiman dan fasilitas umum pedesaan. Mata pencaharian penduduk lokal pada umumnya adalah bertani dengan mengusahakan padi dan palawija [1]. Agroekosistem ini dipengaruhi oleh luapan air sungai dan curah hujan [2].

Rawa merupakan lahan yang menempati posisi peralihan antara sistem daratan dan perairan (sungai, danau atau laut) [3]. Pada musim penghujan sebagian daerah rawa tergenang air hujan (banjir), sedangkan pada musim kemarau air pasang hanya mampu mengairi sebagian kecil lahan persawahan penduduk, karena air pasang hanya mampu mencapai sejauh $+0.5-1 \mathrm{~km}$ dari sungai. Hal ini diakibatkan oleh tidak berfungsinya sistem saluran yang ada, sudah tertutup endapan/sedimentasi dan semak-semak. Menurunnya fungsi saluran yang ada merupakan penyebab menurunnya produktifitas pertanian saat ini [4].

Dusun Palambahen merupakan salah satu wilayah yang sebagian besar penduduknya memanfaatkan daerah rawa untuk bercocok tanam, hal ini didukung oleh Pemerintah yang membangun jaringan irigasi memanfaatkan pasangsurut air Sungai Kahayan. Sungai Kahayan sebagai sumber air untuk mengairi areal lahan di lokasi Dusun Palambahen. Secara umum kondisi Daerah Irigasi Rawa (DIR) Palambahen dapat dilihat pada Gambar 1 dan Gambar 2 di bawah ini.

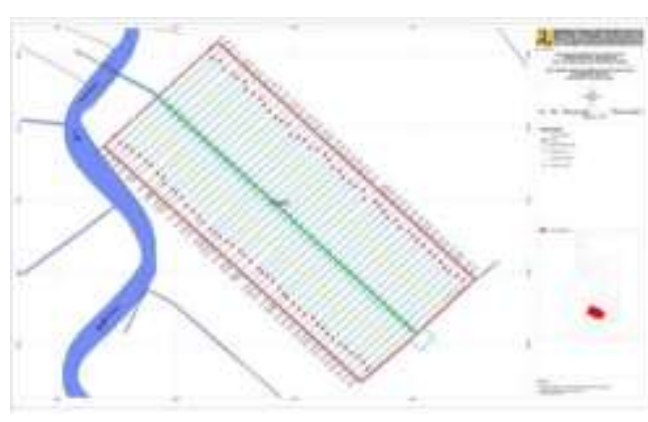

Gambar 1. Peta Daerah Irigasi Rawa Palambahen
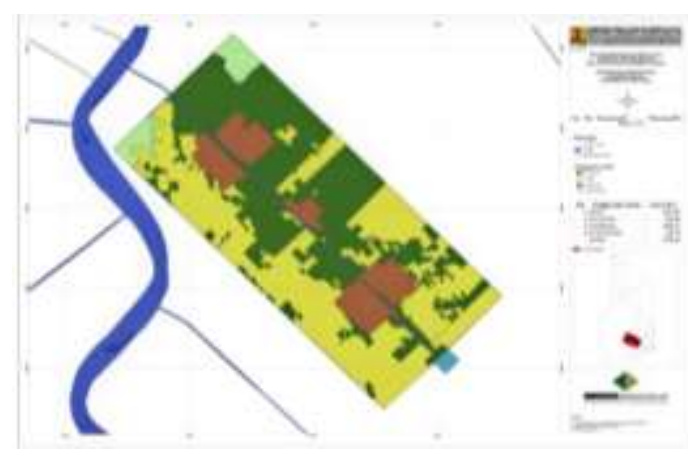

Gambar 2. Peta Penggunaan Lahan Eksisting DIR Palambahen

Berdasarkan data dan informasi awal yang diperoleh dari petani dan Juru Pengairan di Dusun Palambahen, persoalan yang dihadapi oleh para petani adalah telah terjadinya alih fungsi lahan yang mengakibatkan berkurangnya luas lahan sawah menjadi perkebunan serta tidak sampainya air ke ujung saluran sekunder, yang dikenal dengan istilah Ray, terutama pada saat musim kemarau, baik yang disebabkan karena siklus pasang yang terlalu cepat maupun disebabkan karena adanya hambatan di saluran berupa sedimentasi sehingga lahan sawah di bagian ujung saluran menjadi overdrain yang mengakibatkan meningkatnya kadar keasaman tanah.

Pada tingkatan tertentu, kadar keasaman tanah dapat berdampak pada kematian tanaman padi pada masa pertumbuhan. Dengan seringnya kerusakan tanaman padi akibat tingkat keasaman tanah, maka sebagian petani yang mengalami kerugian secara materi 
memutuskan untuk mengalih fungsikan lahannya dengan menanam tanaman kayu yang menurut mereka resiko kerugian relatif kecil.

Terdapat beberapa pustaka atau hasil kajian sebelumnya yang membahas tentang daerah irigasi rawa pasang surut yang menjadi referensi dalam melaksanakan penelitian ini sehingga diharapkan hasil penelitian ini lebih lengkap, diantaranya adalah :

Tata Cara Perencanaan Teknik Jaringan Irigasi Rawa oleh Yulianti Santi Eka Putri dan Andojo Wurjanto, dimana hasil penelitiannya menyatakan bahwa detail desain dalam pekerjaan perencanaan jaringan irigasi rawa berupa pintu air. Perencanaan desain pintu air berdasarkan rata-rata elevasi muka air saluran yang diperoleh dari simulasi HEC-RAS 4.1.0 untuk tinggi dan menyesuaikan dengan lebar saluran untuk dimensi lebar pintu. Detail desain untuk perhitungan pintu air mencakup: perhitungan dimensi, perhitungan hidraulika, perhitungan stabilitas konstruksi, perhitungan struktur.

Strategi Pengembangan Lahan Irigasi Rawa Di Daerah Rawa Pasang Surut Belawang-Kalimantan Selatan, oleh Elias Wijaya Panggabean dan Bangkit Aditya Wiryawan dengan hasil penelitian yang menyatakan bahwa Daerah reklamasi rawa unit Belawang yang pada awalnya dibuka untuk pertanian saat ini sudah semakin terdesak oleh perkembangan karet dan kepala sawit. Dari hasil diskusi dan pengamatan di lapangan diperoleh data bahwa faktorfaktor determinan yang menjadi pendorong dan penghambat pengembangan irigasi rawa untuk pertanian.

Simulasi dan analisis Sistem tata Kelola Air di Lahan Pasang Surut: Studi Awal pada Perkebunan Kelapa Sawit di Kalimantan Selatan oleh Henny Lydiasari dan Winarna yang menyimpulkan bahwa hasil kajian awal diperoleh bahwa sistem tata kelola air yang diterapkan belum efektif sehingga masih diperoleh cakupan genangan yang cukup luas pada blok pengamatan. Kondisi ini terjadi pada bulan Desember hingga Maret yang melebihi dari batas maksimum tergenang yaitu 3 minggu.

Dan yang terakhir, Kajian Optimalisasi Sistem Irigasi Rawa (Studi Kasus Daerah Rawa Semangga Kabupaten Merauke Propinsi Papua) oleh Darwin Pakpahan, Suripin dan Sri Sangkawati Sachro yang mendapatkan kesimpulan bahwa Optimalisasi Daerah Rawa Semangga dilakukan melalui pengembangan daerah layanan jaringan rawa Semangga sesuai rencana pola tanam III dengan 4 (empat) penanganan.

Berdasarkan identifikasi masalah dan penelitian terdahulu yang ditemukan, maka beberapa masalah tersebut adalah 1) Besarnya luas lahan sawah yang telah beralih fungsi menjadi lahan lainnya; 2) Tingkat kesesuaian lahan di areal DIR Palambahen; 3) Karakteristik pasang surut di DIR Palambahen; dan 4) Apakah air pasang yang terjadi dapat mengairi areal di bagian ujung saluran sekunder ?

Oleh karena itu, penelitian ini dilakukan dengan tujuan 1) Mengetahui tingkat perubahan tata guna lahan pada DIR Palambahen; 2) Mengetahui tingkat kesesuaian lahan pada areal DIR Palambahen; 3) Mengetahui karakteristik pasang surut pada DIR Palambahen; dan 4) Mengetahui ketercapaian air pasang pada ujung saluran sekunder dan upaya yang dapat dilakukan untuk membantu pemenuhan kebutuhan air di areal ujung saluran.

\section{METODE PENELITIAN}

Dalam melaksanakan penelitian ini akan dibagi dalam beberapa tahapan 
kegiatan sebagai berikut:

1. Melakukan studi literatur dan pustaka yang terkait dengan pokok bahasan penelitian;

2. Melakukan pengumpulan data sekunder terkait kondisi Daerah Irigasi Rawa di Desa Palambahen;

3. Melakukan analisis terhadap penggunaan lahan di areal DIR Palambahen;

4. Melakukan analisis data pengamatan pasang surut dan lokasi terjauh yang dapat dialiri oleh air pasang pada saluran sekunder (Ray)

5. Menentukan konsep rencana pengembangan dengan perencanaan bangunan pintu dan atau pemanfaatan teknologi pompa untuk membantu upaya memenuhi kebutuhan air di bagian ujung saluran sekunder (Ray)[5].

6. Menyusun kesimpulan penelitian berdasarkan parameter yang diketahui terkait kondisi lahan dan jaringan irigasi rawa Desa Palambahen dan rekomendasi rencana pengembangan.

\section{Pengumpulan Data Primer dan Data Sekunder}

1. Pengumpulan data primer dengan pengamatan pasang surut yang telah dilaksanakan;

2. Pengamatan Penggunaan Lahan Eksisting dengan menggunakan Drone.

3. Kegiatan pengumpulan data sekunder dilakukan terhadap datadata:
a. Data dan peta penggunaan lahan areal irigasi Desa Palambahen tahun 2014 dan tahun 2019;
b. Data kondisi saluran dan

bangunan pintu air;

c. Data hidrologi dan klimatologi dari pencatatan yang berada di sekitar lokasi DIR Palambahen

4. Pengumpulan data penggunaan lahan eksisting dan alih fungsi lahan yang berkembang.

\section{HASIL DAN PEMBAHASAN}

\section{Penggunaan Lahan Eksisting DIR Palambahen}

Kegiatan survey dan inventarisasi penggunaan lahan pada DIR Palambahen dilakukan dengan metode visualisasi udara menggunakan Drone DJI Panthom 4 yang selanjutnya diinterpretasikan dengan citra satelit dan dituangkan dalam peta penggunaan lahan pada DIR Palambahen.

Pengambilan visualisasi udara dilaksanakan di seluruh areal lahan DIR Palambahen, mulai dari Sungai Kahayan sebagai sumber air utama, kemudian pada bagian hulu saluran Primer dan dilanjutkan pengambilan visualisasi udara pada bagian tengah areal DIR Palambahen, sampai pada bagian hilir saluran Primer yang masuk ke dalam kolam pasang yang ada pada bagian ujung areal DIR Palambahen seperti nampak pada Gambar 3 di bawah ini.

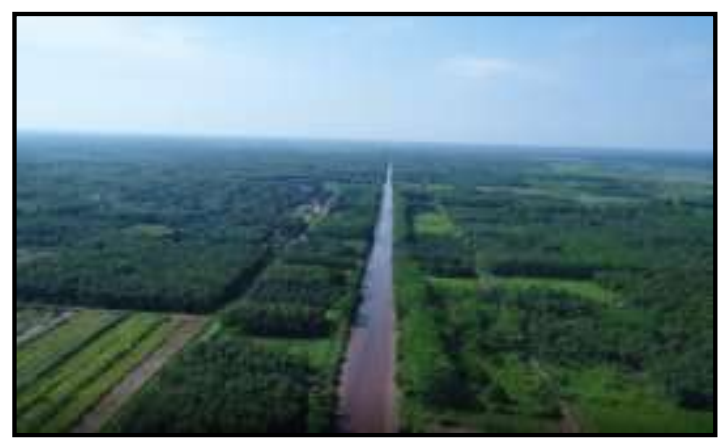

Gambar 3. Penggunaan Lahan DIR Palambahen 
Tabel 1. Penggunaan Lahan Daerah Irigasi Rawa Palambahen

\begin{tabular}{|c|c|c|c|c|}
\hline Penggunaan Lahan & 2014 & 2019 & Selisih & Perubahan \\
\hline Sawah & 1850.00 & 1611.00 & -239.00 & $-12.92 \%$ \\
\hline Kebun & 258.62 & 1543.21 & 1284.59 & $496.71 \%$ \\
\hline Belukar & 1248.54 & 136.79 & -1111.75 & $-89.04 \%$ \\
\hline Permukiman & 375.84 & 442.00 & 66.16 & $17.60 \%$ \\
\hline Total & 3733.00 & 3733.00 & & \\
\hline
\end{tabular}

\section{Tingkat Kesesuaian Lahan di Area DIR Palambahen}

Berdasarkan hasil analisis pada 12 titik lokasi pengambilan sampel tanah untuk pengujian laboratorium tanah pertanian serta survey dan pengamatan visual dengan sebaran luasan setiap 250 Hektar serta dianalisis kesesuaian lahannya menurut Peraturan Menteri Pertanian Nomor 79/Permentan/ OT.140/8/2013, dapat disimpulkan bahwa areal lahan di lokasi DIR Palambahen termasuk dalam kategori sesuai untuk lahan padi dan palawija serta untuk perkebunan tanaman keras di bagian Timur dengan peningkatan pola pengaturan yang lebih baik agar dicapai hasil produksi yang optimal. Beberapa contoh hasil analisis kesesuaian lahan dapat dilihat pada Tabel 2 di bawah ini.

Tabel 2. Beberapa Hasil Analisis Kesesuaian Lahan

\begin{tabular}{|c|c|c|c|c|}
\hline No & Jenis Analisis & Keterangan & Kesesuaian Lahan & Kesimpulan \\
\hline 1 & $\begin{array}{l}\text { Koordinat } \\
\text { Vegetasi Dominan } \\
\left.\text { Temperatur ( }{ }^{\circ} \mathrm{C}\right) \\
\text { Kriteria Drainase } \\
\text { pH H2O } \\
\text { N Total (\%) } \\
\text { Salinitas } \\
\text { Lereng (\%) } \\
\text { Batuan di permukaan }\end{array}$ & 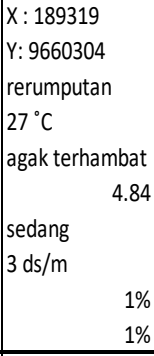 & $\begin{array}{l}\mathrm{S} 2 \\
\mathrm{~S} 2 \\
\mathrm{~S} 2\end{array}$ & 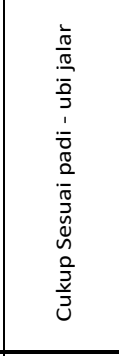 \\
\hline 2 & $\begin{array}{l}\text { Koordinat } \\
\text { Vegetasi Dominan } \\
\text { Temperatur }\left({ }^{\circ} \mathrm{C}\right) \\
\text { Kriteria Drainase } \\
\text { pH H2O } \\
\text { N Total (\%) } \\
\text { Salinitas } \\
\text { Lereng (\%) } \\
\text { Batuan di permukaan }\end{array}$ & 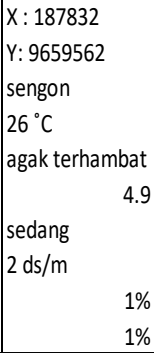 & $\begin{array}{l}\mathrm{S} 1 \\
\mathrm{~S} 1 \\
\mathrm{~S} 1 \\
\mathrm{~S} 1\end{array}$ & 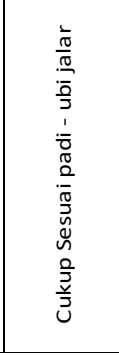 \\
\hline
\end{tabular}

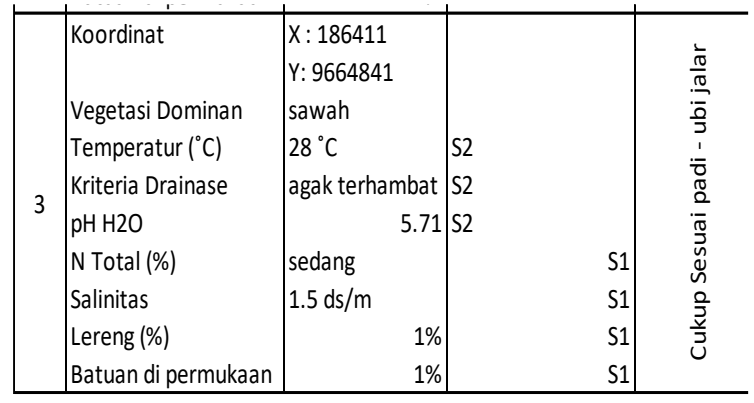

Data Pengamatan Pasang Surut Sungai Kahayan Sebagai Sumber Air Utama Daerah Irigasi Rawa Palambahen

Pengamatan pasang surut dilakukan menggunakan tide staff (papan pasang surut) yang telah diberi skala dalam meter atau centimeter [6]. Bahan tide staff (papan pasang surut) yang digunakan dapat terbuat dari kayu, alumunium atau bahan lain yang di cat anti karat.

Pada tahun 1928, Doodson mengenalkan metode yang amat praktis untuk analisis pasang surut dari pengamatan 15 atau 29 hari (15/29 Piatan), yang kemudian terkenal dengan sebutan Admiralty Method of Analysis Of Tide. Pada metode perhitungan metode Admiralty digunakan untuk menghitung dua konstanta harmonik dari data pasang surut yang ada. Dalam metode Admiralty harus mencari nilai amplitudo dan phasa sesaat dari masing-masing komponen [7].

Hasil analisis pengamatan pasang surut di Desa Palambahen adalah sebagai berikut: HHWL $=5.000 \quad \mathrm{~m}$ MHWL $=4.685 \quad \mathrm{~m}$ MSL $=3.236 \quad \mathrm{~m}$ MLWL $=1.788 \quad \mathrm{~m}$ 


$\begin{array}{lll}\text { CDL } & =1.742 & \mathrm{~m} \\ \text { LLWL } & =1.473 & \mathrm{~m} \\ \text { LAT } & =1.352 & \mathrm{~m} \\ \text { LAT } & =1.352 & \mathrm{~m}\end{array}$

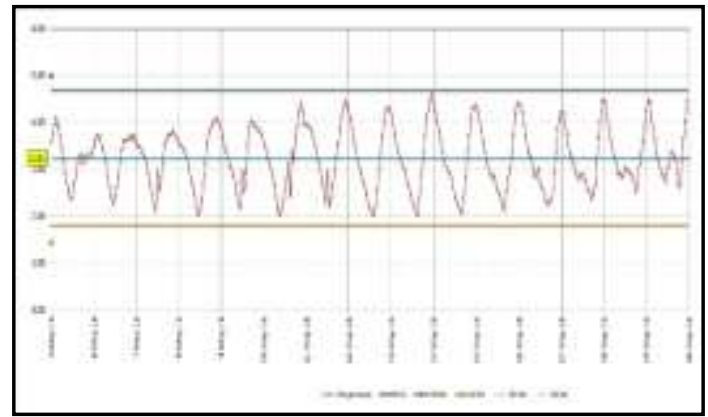

Gambar 4. Hasil Pengamatan Pasang Surut

Berdasarkan hasil pengamatan dan analisis data pasang surut diketahui bahwa elevasi pasang tertinggi (HHWL) berada pada $+5 \mathrm{mdpl}$, sehingga beberapa areal pertanian pada elevasi di atas +5 mdpl tidak dapat terairi oleh air pasang, sehingga diperlukan alternatif perencanaan teknis untuk membantu suplai air ke areal lahan tersebut.

\section{Pemanfaatan Pompa Irigasi}

Irigasi pompa merupakan alternatif terakhir ketika proses pemanfaatan air pasang tidak dapat memenuhi kebutuhan air pada lahan. (Kalsim, 2001: 19)[8].

Salah satu upaya yang dapat dilakukan untuk memenuhi kebutuhan air di bagian ujung saluran sekunder (Ray) adalah dengan penggunaan pompa, namun demikian perlu dikaji secara detail terkait pengadaan dan kegiatan operasi serta pemeliharaan pompa, apakah menjadi tanggungjawab setiap petani atau dapat dikelola dalam kelompok-kelompok tani yang ada.

\section{KESIMPULAN}

Berdasarkan hasil analisis yang telah dilakukan dalam penelitian ini, dapat diperoleh beberapa kesimpulan yaitu Sebagian besar areal lahan merupakan sawah (1611 Ha) dan kebun (1543.21 Ha) yang telah mengalami proses alih fungsi lahan sejak tahun 2014 hingga tahun 2019. Areal lahan di lokasi termasuk dalam kategori sesuai untuk lahan padi dan palawija serta untuk perkebunan tanaman keras. Permasalahan lain yang terjadi adalah ketika pasang, air pasang tidak mampu mencapai ujung saluran sehingga berpengaruh pada proses kegiatan tanam. Dalam hal ini salah satu upaya yang dapat dilakukan untuk memenuhi kebutuhan air di bagian ujung saluran sekunder (Ray) adalah dengan penggunaan pompa, namun demikian perlu dikaji secara detail terkait pengadaan dan kegiatan operasi serta pemeliharaan pompa.

Berdasarkan hasil penelitian ini sebagaimana telah disimpulkan di atas, Penulis dapat menyusun beberapa saran dan rekomendasi kepada instansi terkait, diantaranya adalah 1) Instansi yang berwenang dalam pengelolaan DIR Palambahen, dapat melaksanakan kajian lebih mendalam terkait pemenuhan kebutuhan air pada daerah di ujung saluran sekunder dengan alternatif pemanfaatan teknologi pompa; 2) Setiap pemangku kepentingan (Stake holder) terkait jaringan irigasi Desa Palambahen perlu melakukan gerakan bersama sebagai upaya mempertahankan dan memperbaiki kondisi jaringan irigasi Desa Palambahen agar tetap terjaga sebagai salah satu daerah lumbung padi yang mensuplai kebutuhan di Kabupaten Pulang Pisau dan sekitarnya; dan 3) Para Akademisi, baik mahasiswa maupun Perguruan Tinggi dapat melaksanakan penelitian dan kajian tentang irigasi pasang surut di lokasi lain sebagai upaya mendukung program pemerintah daerah dan pemerintah pusat terkait ketahanan pangan 


\section{DAFTAR PUSTAKA}

[1] Balai Wilayah Sungai Kalimantan II, (2019), Penyusunan Penilaian Kinerja dan AKNOP DIR Tahai, DIR Belanti I Kab. Pulang Pisau Kalimantan Tengah.

[2] Suparwoto, (2019), Budi Daya dan Adaptasi Varietas Unggul Baru Padi pada Lahan Rawa Lebak Sumatera Selatan, 1.

[3] Putri YSE dan Wurjanto A, (2016), Tata Cara Perencanaan Teknik Jaringan Irigasi Rawa, 3.

[4] Balai Wilayah Sungai Kalimantan II, (2016), DED DR Handil Masyarakat Desa Palampahean Kec. Pandih Batu.

[5] Panggabean Elias W dan Wiryawan Bangkit A, (2016), Strategi Pengembangan Lahan Irigasi Rawa Di Daerah Rawa Pasang Surut Belawang-Kalimantan Selatan, 2.

[6] Kementerian Pekerjaan Umum dan Perumahan Rakyat, 2015, Peraturan Menteri Pekerjaan Umum dan Perumahan Rakyat Nomor 11/PRT/M/2015, tanggal 6 April 2015 Tentang Eksploitsi dan Pemeliharaan Jaringan Reklamasi Rawa Pasang Surut.

[7] Pakpahan D, Suripin dan Sachro Sri S, (2015), Kajian Optimalisasi Sistem Irigasi Rawa (Studi Kasus Daerah Rawa Semangga Kabupaten Merauke Propinsi Papua), 3.

[8] Kadiran, (1999), Manfaat Penggunaan Pompa Irigasi Di Daerah Pasang Surut Tipe Luapan C dan D Di Wilayah Sumatera Selatan, 3. 